\title{
Bracing Biophilia: When biophilic design promotes pupil's attentional performance, perceived restorativeness and affiliation with Nature
}

\author{
Giuseppe Barbiero $^{1}$ (D) Rita Berto ${ }^{1} \cdot$ Alice Venturella $^{1} \cdot$ Nicola Maculan $^{1}$
}

Received: 27 April 2021 / Accepted: 11 October 2021

(c) The Author(s) 2021

\begin{abstract}
Biophilic design is an architectural model that offers the possibility to create the Naturebased Innovative Learning Environment (ILE), which might support cognitive processes and stimulate affiliation with Nature. Bracing Biophilia is an exploratory research programme which verifies the effect of Nature-based ILEs on pupils' attentional performance and affiliation with Nature. We compared a conventional learning environment with two Nature-based environments made according to biophilic design and the Biophilic Quality Index (BQI). The experimental observations spanned three school years; they were carried out within a conventional learning environment in the first year and in a biophilic designed one in the next two. Measurements, that is the administration of the Perceived Restorativeness Scale-children, the Continuous Performance test, and the Connectedness to Nature Scale-children, were deployed at regular intervals at three different times (autumn, winter, spring) of each school year. Results show that learning environments with biophilic design, in addition to being preferred and perceived as more restorative, are more effective in supporting pupils' attentional performance than conventional learning environments and, over time, strengthen the feeling of affiliation with Nature. A BQI certified biophilic design learning environment turns out to be the best of all indoor environments and just below the outdoor learning environment used as a comparison of biophilic design indoor environment. Although the objective limitation of this study is the number of pupils, the trend appears clear and cannot be attributed to pupils' cognitive maturation processes. This case study allows us to appreciate the importance of the restorative learning environments with biophilic design capable of supporting the learning process and strengthening the affiliation with Nature.
\end{abstract}

Keywords Affiliation with nature $\cdot$ Attentional performance $\cdot$ Biophilic design $\cdot$ Biophilic Quality Index $(\mathrm{BQI}) \cdot$ Innovative Learning Environment (ILE) · Restorative environments

In this paper, "Nature" is written with the capital "N" to indicate the biosphere and the abiotic matrices (soil, air, and water) where it flourishes, and to avoid confusion with "nature" as the intrinsic quality of a certain creature and/or phenomenon.

Giuseppe Barbiero

g.barbiero@univda.it

Extended author information available on the last page of the article 


\section{Introduction}

Educational theorists and practitioners have always recognized the importance of physical space in an early learning environment, they argue that a child's environment is crucial to the physical and cognitive development and that educational environments should be rich in stimuli, providing opportunity for exploration and testing (Moore, 1987). The physical environment should facilitate a child's sense of competence, i.e. the capacity to explore the physical world with independence, creating opportunities for learning and play (Maxwell, 2007). To this end, school design has focussed on the three specific dimensions believed to be the most influential in early learning: (1) space fostering exploration, independence and the development of child's sense of self and willingness to play, (2) spatial quality (through colour, light, materials, etc.) and (3) integration of the outdoor and the indoor environment (Moore \& Sugiyama, 2007). However, school environments should not only provide a balance between individual capabilities and environmental challenge, but also giving the child the opportunity to avoid mental fatigue to sustain learning (Kuo et al., 2018). Ideally, this kind of school environment has no environmental stressors which challenge the child subtracting resources to the ongoing task; in addition to that, this type of environment offers non-competitive stimuli that is stimuli that positively engage attention without distracting the child too much and keeps an eye on Nature directly or indirectly (Kuo et al., 2019). To accomplish this aim, school environments should be designed according to the principles of attention restoration theory (ART; Kaplan, 1995), which suggests how attentional capacity can be restored through exposure to Nature (Adams \& Savahl, 2017; Berto et al., 2015; Dadvand et al., 2015). Therefore, when attentional fatigue concerns primary school children restoration should go through a biophilic designed learning environment (Hartig et al., 2008).

The biophilic design is an architectural design model based on the biophilia hypothesis (Kellert \& Wilson, 1993; Wilson, 1984). According to Edward O. Wilson, biophilia is the innate human tendency to be fascinated by Nature and, in some circumstances, to become emotionally affiliated with it (Wilson, 2002). Moving from this definition of biophilia, Stephen Kellert defines biophilic design as the deliberate attempt to design environments consistent with our tendency to become affiliated with natural systems and processes (Kellert, 2008). Biophilic design is organised into patterns (Browning et al., 2014; Kellert, 2018) characterised by an evolutionary source (Barbiero \& Berto, 2021; Bolten \& Barbiero, 2020) which has proven effective under experimental conditions (Berto et al., 2020). The biophilic design has also been implemented in advanced building certification protocols, such as Living Building Challenge ${ }^{\circledR}$ and WELL ${ }^{\circledR}$ (Sturgeon, 2017).

The biophilic design offers the possibility to create new and innovative Nature-based learning environments. Innovative Learning Environment (ILE) is considered a key element in the development of a society and has become part of the agenda of the Organisation for Economic Co-operation and Development (OECD, 2013, 2015), which suggests intervening on learning ecosystems to improve students' performance (OECD, 2017). A "learning ecosystem" is when the architectural project meets the educational project in an interactive process, namely a project that includes the activity and the outcomes of the learning in relation to environment (Barbiero, 2009; Camino et al., 2009). However, the analysis of the existing relationships between psychophysical wellbeing, school performance, and Nature-based learning environment is a relatively new topic, not yet well investigated. 
In this paper, we present Bracing Biophilia, a research programme devoted to study Nature-based learning environments able to support pupils' cognitive processes and stimulate their biophilia. The experimental observations took place in a rural school located on the western Alps near Monte Rosa, which serves the local community of Gressoney-LaTrinite (Italy). The school was chosen because it is immersed in a well-preserved natural environment, and it allows also carrying out educational activities in a natural outdoor environment. With Bracing Biophilia, we compared a conventional learning space with two Nature-based learning environments made according to biophilic design. The experimental observations of the Bracing Biophilia project spanned three school years. This allowed us to compare the effect of different learning environments on the attention restoration process, after the state of mental fatigue produced by a lesson. Attention is a key factor for predicting school performance (Kuo et al., 2018; OECD, 2017); our attempt is to verify if school environments created with biophilic design and the Biophilic Quality Index (BQI; Berto \& Barbiero, 2017b) offers an advantage from the attentional point of view.

Bracing Biophilia is the ideal continuation of the Standard of Étroubles, a series of experimental observations conducted in Nature on a group of pupils from a urban school (Barbiero \& Berto, 2016). The Standard of Étroubles had shown that (1) children can perceive the restorative value of different environments, and that (2) an alpine forest triggers involuntary attention in children and restores their attentional performance more than the classroom and the school courtyard (Berto et al., 2015). However, the Standard of Étroubles did not detect significant changes in the children's affiliation with Nature. The most likely explanation is that the occasional outdoor activities carried out in a urban school may not be enough to change the feeling of affiliation with Nature. Bracing Biophilia exceeds the limits of the Standard of Étroubles insofar as the pupils' sporadic contact with Nature. The pupils of Gressoney-La-Trinité, participating in this study, lived every day in a well-preserved natural environment. However, pupils spent many hours of the day in a conventional indoor learning environment. Bracing Biophilia is an educational programme combining an outdoor learning environment and an innovative biophilic designed indoor environment, so as to stimulate biophilia and promote psychophysical restoration (Venturella \& Barbiero, 2021). Since the biophilic design aims to foster permanent contact with Nature (Kellert, 2018), we sought to verify whether continuous biophilic stimulation for a long enough time would change the pupils' feelings of affiliation with Nature. To our notice, Bracing Biophilia is the first longitudinal study that follows the evolution of a group of primary school pupils' affiliation with Nature, one that was offered a Nature-based learning environments. If the biophilia hypothesis proposed by E.O. Wilson (2002) is correct, then living in environments that will stimulate biophilia should improve the capacity to recover from mental fatigue (Berto, 2005; Kaplan, 1995) and, as a result, school performance should also improve (Kuo et al., 2018).

\section{The case study: Materials and method}

\subsection{Subjects}

The experimental observations involved the 18-20 pupils, aged from 6 to 11 years, of the Gressoney-La-Trinité primary school. Before starting the study, the pupils' parents were given detailed information on all the instruments of investigation that would be used, and on all phases of the experimental observations. The parents gave their written consent, 
compliant with the new EU regulations, and the entire research project was approved by the Research Ethics Committee of the University of Valle d'Aosta.

\subsection{Experimental settings}

\subsubsection{The outdoor learning environment}

The primary school of Gressoney-la-Trinite is a rural mountain school built in 1960 which serves a local community of about 300 people. Gressoney-La-Trinité is a mountain village (1635 m a.s.1.) located in the upper Lys valley on the side of the Monte Rosa Italian Alps. Gressoney-La-Trinité has a typically alpine landscape with meadows and woods, mainly conifers (Abies alba, Picea abies, Pinus, Larix decidua) and deciduous mountain trees (Betula, Fagus sylvatica, Ulmus glabra). This learning environment, shown in Fig. 1, was used for the experimental outdoor observations.

\subsubsection{The conventional classroom}

As Fig. 2 shows, the school object of the study consists of three classrooms: A large classroom, a small classroom and a multipurpose classroom used mainly as a canteen. Until the summer 2017, the school maintained its original layout, with the three classrooms offering together a conventional learning environment as shown in Fig. 3.

\subsubsection{The biophilic designed classroom}

During the 2017 summer vacation, the building requalification works were carried out on the school's indoor spaces to transform this conventional learning environment into a biophilic designed learning environment (Barbiero et al., 2017). This concerned three areas of the school that is the large classroom, the small classroom, and multipurpose classroom, to which were applied all 14 biophilic design patterns (Browning et al., 2014), distributed as shown in Table 1.
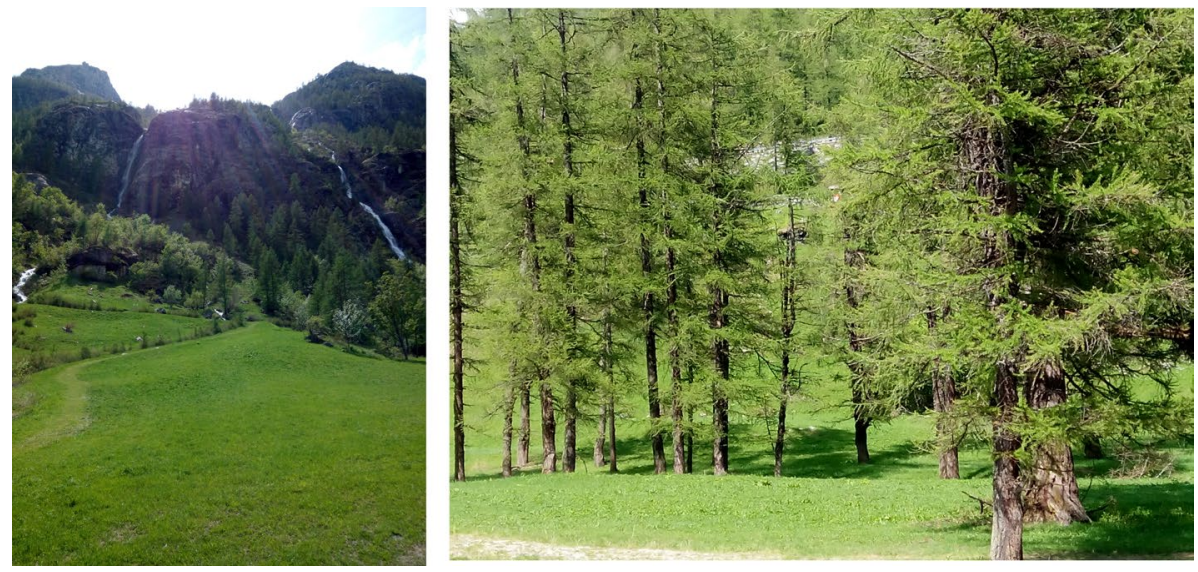

Fig. 1 Gressoney-La-Trinité school surroundings 


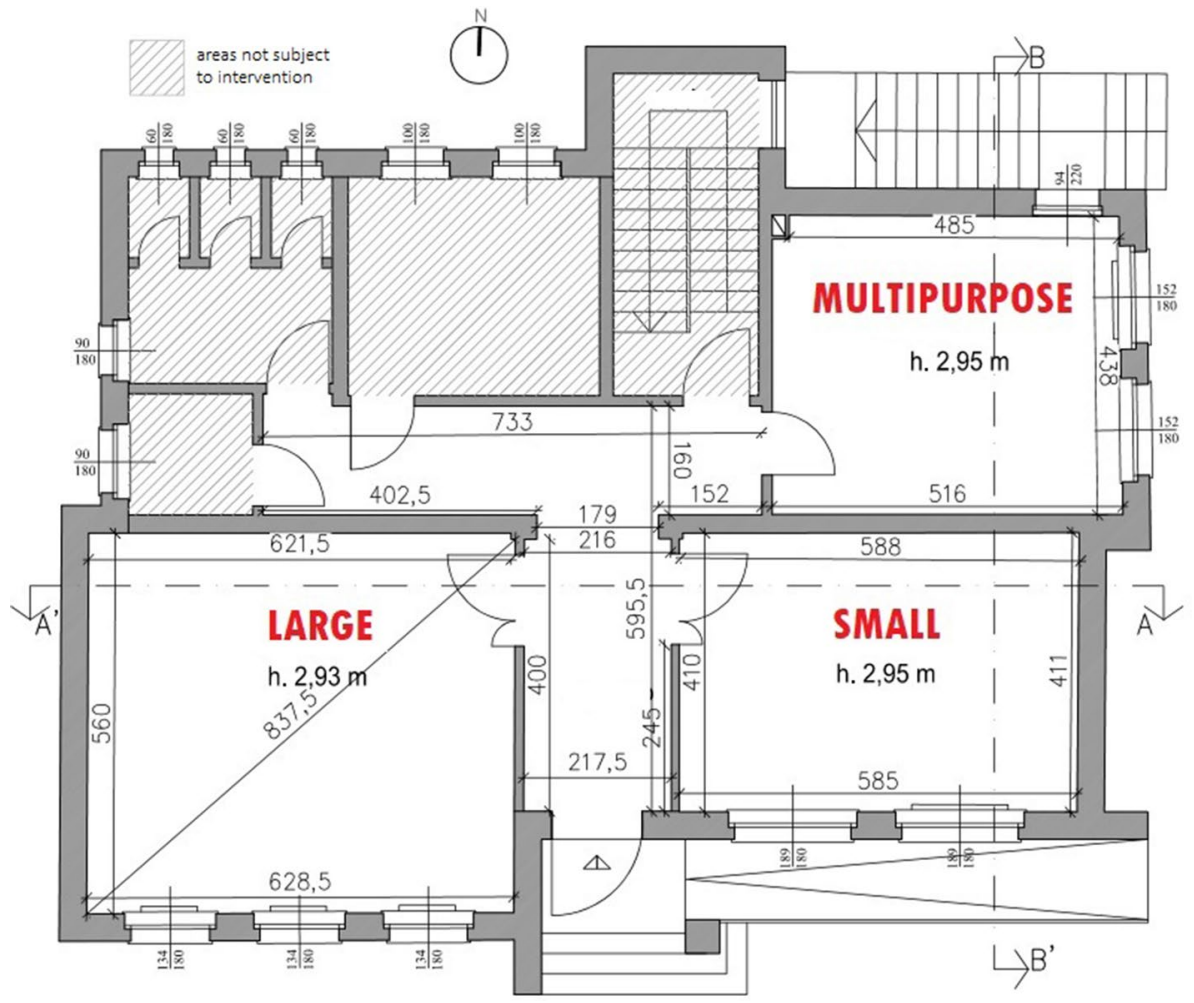

Fig. 2 Gressoney-La-Trinité primary school plan
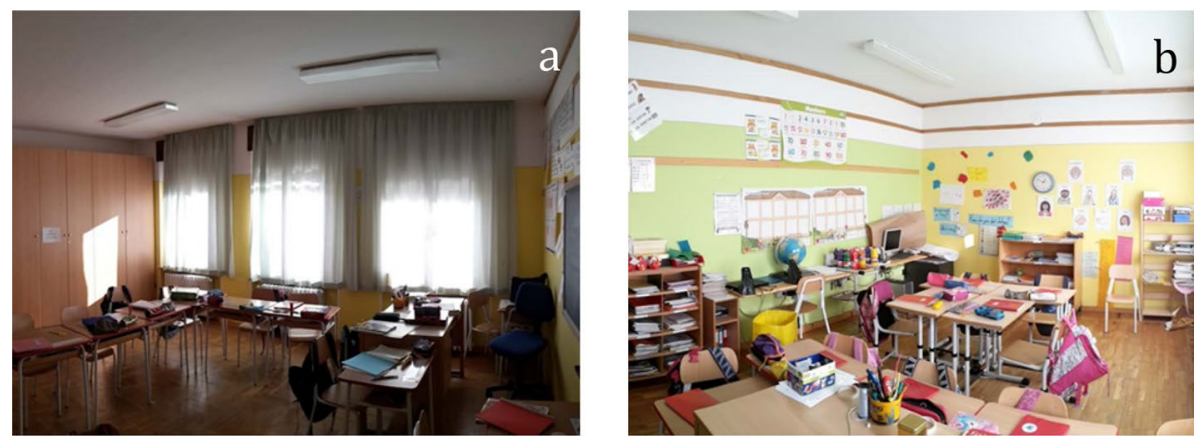

Fig. 3 The classrooms before the building requalification. The large classroom (a) and the small classroom (b)

To foster restoration from mental fatigue e nurture biophilia, pupils were offered a stimulating environment enriched with diversified elements and materials. The new materials allow the pupil to work around his/her emotions because the colour, light, materials, texture, and smell are related to new experiences and feelings, while the new layout offers the pupil opportunities to have a break from the "usual", taking a different 
Table 1 The presence (indicated by a dot) of the 14 biophilic design patterns in the three classrooms after the building requalification works

\begin{tabular}{lllll}
\hline & Patterns of Biophilic Design & Large & Small & Multipurpose \\
\hline 1 & Visual connection with nature & O & O & O \\
2 & Non-visual connection with nature & O & O & O \\
3 & Non-rhythmic sensory stimuli & & & O \\
4 & Thermal and airflow variability & O & O & O \\
5 & Presence of Water & & & O \\
6 & Dynamic and diffuse light & O & O & O \\
7 & Connections with natural systems & O & & $\mathrm{O}$ \\
8 & Biomorphic forms and patterns & O & O & \\
9 & Material connection with nature & O & O & O \\
10 & Complexity and order & O & O & O \\
11 & Prospect & O & O & \\
12 & Refuge & O & O & \\
13 & Mystery & O & & O \\
14 & Risk and peril & & & O \\
\hline
\end{tabular}

perspective, creating free play or acting new activities. For example, the visual connection with Nature (pattern 1) was improved with curtains that protect from the sunlight but, at the same time allow you to see and maintain your contact with the outdoor environment, as in Fig. 4b. Special attention was paid to diffused and dynamic lighting (pattern 6), as shown in Fig. 4, and to temperature variability and air flow (pattern 4) which are controlled by a mechanical ventilation system. In the large classroom, a refuge corner was created (pattern 12), namely a space where pupils can retreat, alone or in a small group, to ease mental fatigue. This corner shown in Fig. $4 \mathrm{~b}$ offers whether a sense of protection or the opportunity of being away for a while from the school routine. Figure 5 shows the small classroom, with details of the prospect corner (pattern 11, Fig. 5b). Thanks to the steps, the pupil can look at the usual environment from
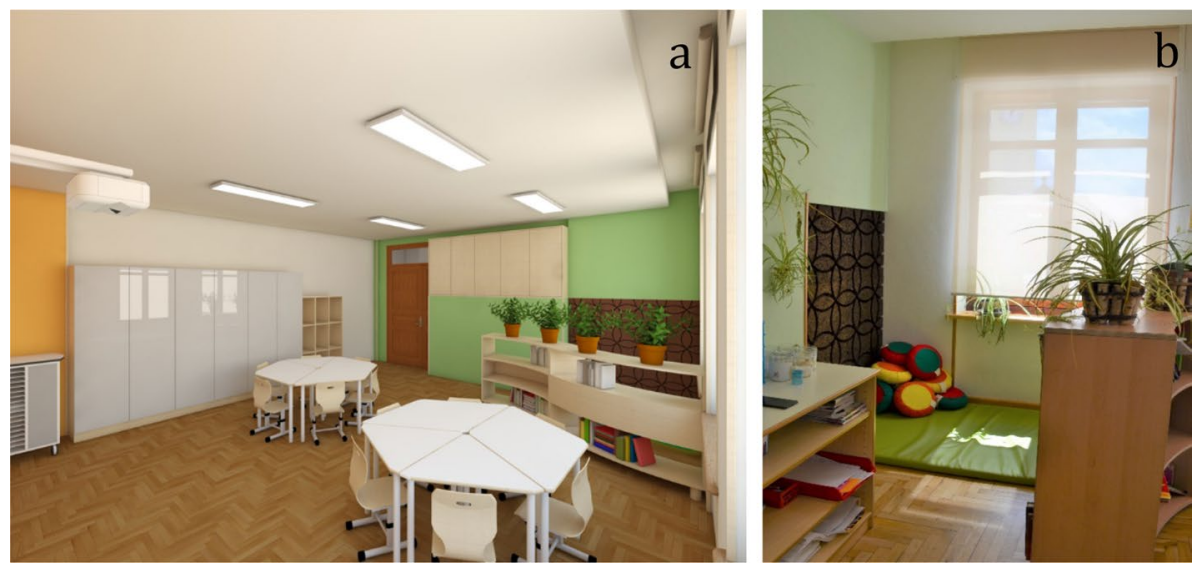

Fig. 4 Dynamic light and sense of protection 

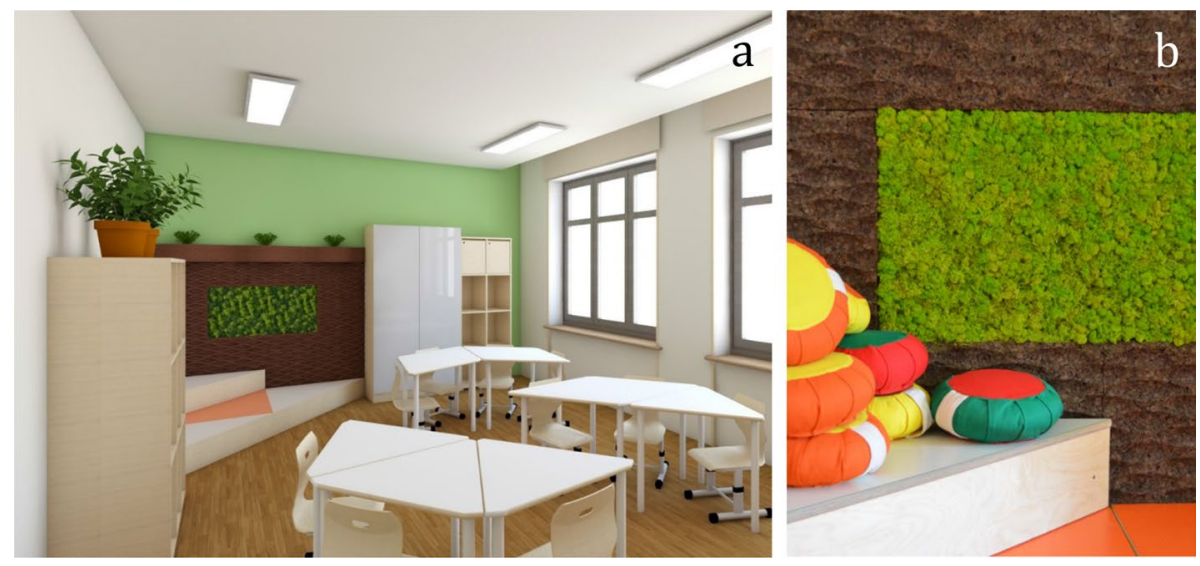

Fig. 5 Creation of exploration spaces. Brown cork decoration panels with stabilised lichen inserted for tactile and olfactory exploration

a different perspective, because s/he can stand or sit at a different level as shown in Fig. 5a. The connection with natural systems (pattern 7) is guaranteed by the presence of plants, as shown in Figs. 4 and 5. To strengthen the connection with natural systems, plants were chosen by pupils, after a visit to the Vivaio Regionale della Valle d'Aosta (local plant nursery) and the pupils themselves took good care of the plants in the classroom (Venturella \& Barbiero, 2021). The use of brown cork decoration panels (pattern 8) and natural material like the stabilised lichen (pattern 9), presented in Fig. 5b, offers the opportunity for tactile and olfactory exploration (pattern 2) and for fascinating exploration (pattern 13).

\subsubsection{The BQI certified biophilic designed classroom}

In the requalification of the multipurpose classroom, we have also used the BQI certified biophilic design (Berto \& Barbiero, 2017b). The BQI is inspired by the ART principles (Kaplan, 1995) and allows assessing the biophilic quality of an environment and its restorative value. The ART is based on the empirical observations that exposure to vegetation in general fosters psychological wellbeing and produces recovery from directed attention fatigue (Kaplan, 2001). Some elements in natural environments are effortlessly engaging and draw on "fascination", namely involuntary attention. Natural patterns are interesting to us, namely fascinating, and do not seem to require attention at all (Berto et al., 2008). The engagement of involuntary attention, when attending to natural settings, guarantees that directed attention can be restored from fatigue. The opportunity for attention restoration makes an environment "restorative" (Berto, 2005). A biophilic environment provides opportunities for attention restoration that is the environment has not to subtract cognitive resources to cope with environmental stressors, to the ongoing task. The BQI allows us to optimise the restorative aspect of biophilic design. Thus, the multipurpose classroom, presented in Fig. 6, was redesigned following the principles of the BQI certified biophilic design to achieve an indoor school environment prototype as close as possible to the restorative properties of natural outdoor environments (Berto, 2014). 

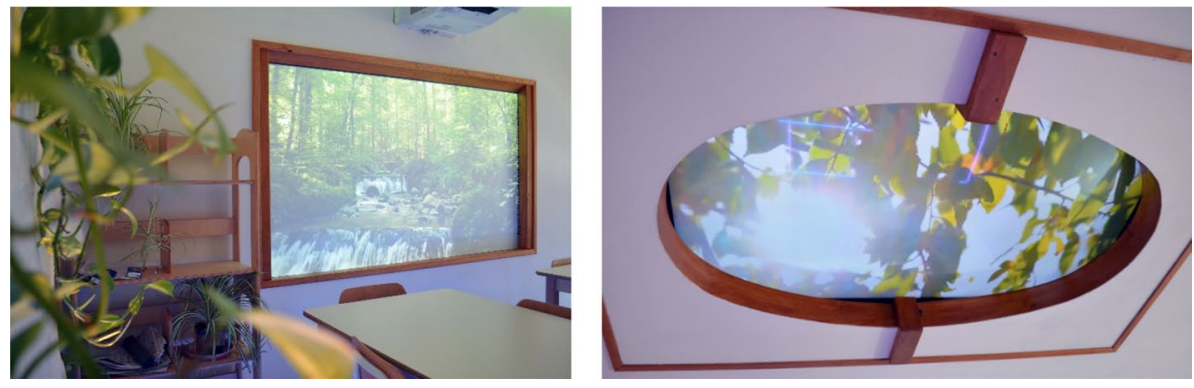

Fig. 6 Details of the multipurpose classroom after the requalification. This classroom was redesigned to meet the restorative criterion of the BQI (Berto \& Barbiero, 2017b)

\subsection{Measurements}

\subsubsection{Perceived Restorativeness and Preference}

To evaluate pupils' perception of restoration attending different school environments, we used the Perceived Restorativeness Scale-children (PRS-ch; Berto et al., 2015). The PRS-ch is based on the ART (Kaplan, 1995) and the adult version of the PRS (Hartig et al., 1997) and was specially built for school-age pupils. The scale is made up of 18 items, of which 17 measure the perception of four restorative factors (being-away, fascination, coherence, scope) and one measures environmental preference, because there is a direct relationship between perceived restoration and environmental preference (Purcell, Peron and Berto, 2001; Hernandez et al., 2001). Each item is rated on a 5-point scale where $0=$ completely disagree and $4=$ completely agree. The restorative value of a place is given by the average of the scores on the 17 items, the item which measures preference is calculated separately. The PRS-ch measures the pupils' perception of an environment's restorative qualities and how much they like that environment.

\subsubsection{Attentional performance}

Perceived restorativeness is normally correlated with improved attentional ability. A restorative environment promotes the activation of involuntary attention, which allows attentional performance to rest and restore (Berto, 2005). The Italian version of the Continuous Performance Test (CPT; Cornoldi et al., 1996) was used to measure the pupils' attentional performance. The CPT is a pencil and paper test which consists of searching for triplets of letters along a string; the test is divided into three subtests, which differ by how the letters are ordered, their size and the spaces between them. The test is a valid tool for measuring attentional performance and inhibition of distracting capacity in children. Although this test is not sensitive to the learning effect (Barbiero et al., 2014; Cornoldi et al., 1996), a different version with new letter strings was used each time. The CPT measures four variables: number of correct answers, number of errors, number of omissions, and test execution time (in sec). 


\subsubsection{Affiliation with Nature}

To assess the feeling of affiliation with Nature, we used the Connectedness to Nature Scale-children (CNS-ch; Berto et al., 2015), based on the scale of Mayer et al. (2004) and adapted to primary school children, which allows us to evaluate the extent to which a child feels part of the natural world, making it a reliable measurement of the construct "affiliation with Nature" of the biophilia hypothesis (Wilson, 2002). The CNS-ch consists of 7 items rated on a 5 -point scale, where $1=$ never and $5=$ always. The average score of the 7 items establishes the measure of the pupil's personal relationship with Nature.

\subsection{Procedure: The longitudinal study}

The experimental observation period extended for three years (2016-2019). In the first school year (2016-2017), the experimental observations were conducted in the school before the building requalification, in a conventional learning environment as shown in Fig. 3. In the following two school years (2017-2018 and 2018-2019), the experimental observations were conducted in the school after the building requalification where the large and small classrooms had taken on a biophilic design configuration, as Fig. 4 and Fig. 5 show, and the multipurpose classroom the BQI certified biophilic design configuration, as Fig. 6 shows. Measurements were deployed at regular intervals at three different times (autumn, winter, spring) of each school year, whilst keeping constant the place and time of day, but randomising the lesson type, the presentation order of the instruments and, where necessary, instrument versions.

In every setting condition, the pupils have had a 50-min lesson. At the end of the lesson, the pupils would take a 5-min break right in the same classroom, after which they would resume didactic activities with a second lesson; the instruments would be deployed $20 \mathrm{~min}$ after the start of the lesson. To determine the existence of differences between the indoor learning environment with biophilic design and the outdoor learning environment, shown in Fig. 1, from which the biophilic design takes its inspiration, the same procedure was also carried out outdoor. Below the results of pupils' average performance are shown in the four conditions: conventional classroom, biophilic designed classroom, BQI certified biophilic designed classroom, and outdoors.

\section{Results}

The biophilic designed classrooms and the BQI certified biophilic designed classroom are both preferred to and perceived as more restorative than the conventional classroom. Figure 7 shows that the BQI certified biophilic designed classroom gets the highest scores for both variables and is the closest to the preference and restorative perception manifested about the natural outdoor learning environment.

As far as the continuous performance test is concerned, each experimental condition confirms the inverse relation between the number of correct answers and reaction time (Barbiero et al., 2014; Berto, 2005; Berto et al., 2015), which is why we only present the trend of correct responses, shown in Fig. 8, and test execution times shown in Fig. 9, in the different learning environments. When the CPT test is administered in a conventional learning environment, the pupils appear slower and less precise. Pupils' 


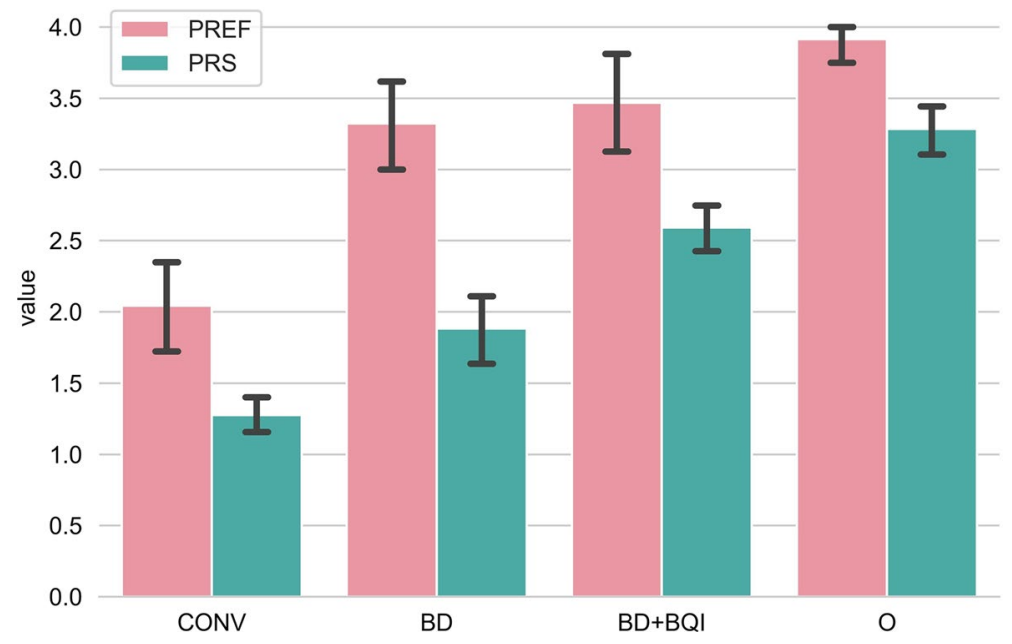

Fig. 7 Average score of Perceived Restorativeness Scale-ch (PRS) and preference (PREF) in the four learning environments. $\mathrm{CONV}=$ conventional classroom; $\mathrm{BD}=$ biophilic designed classroom; $\mathrm{BD}+\mathrm{BQI}=\mathrm{BQI}$ certified biophilic designed classroom; $\mathrm{O}=$ Outdoor

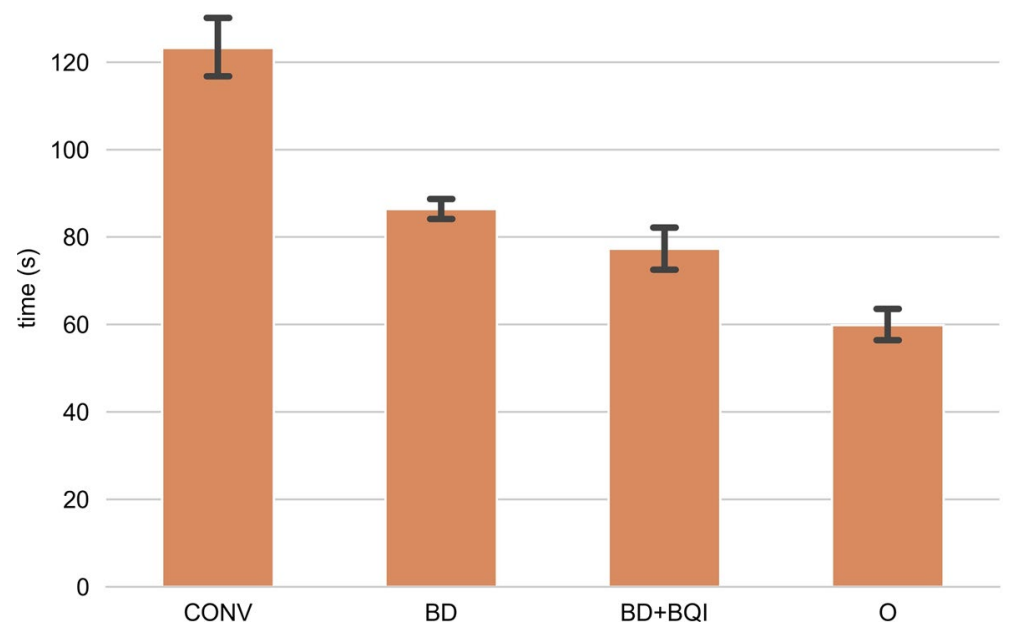

Fig. 8 Average time taken to complete the Continuous Performance Test in the four learning environments. $\mathrm{CONV}=$ conventional classroom; $\mathrm{BD}=$ biophilic designed classroom; $\mathrm{BD}+\mathrm{BQI}=\mathrm{BQI}$ certified biophilic designed classroom; $\mathrm{O}=$ Outdoor 


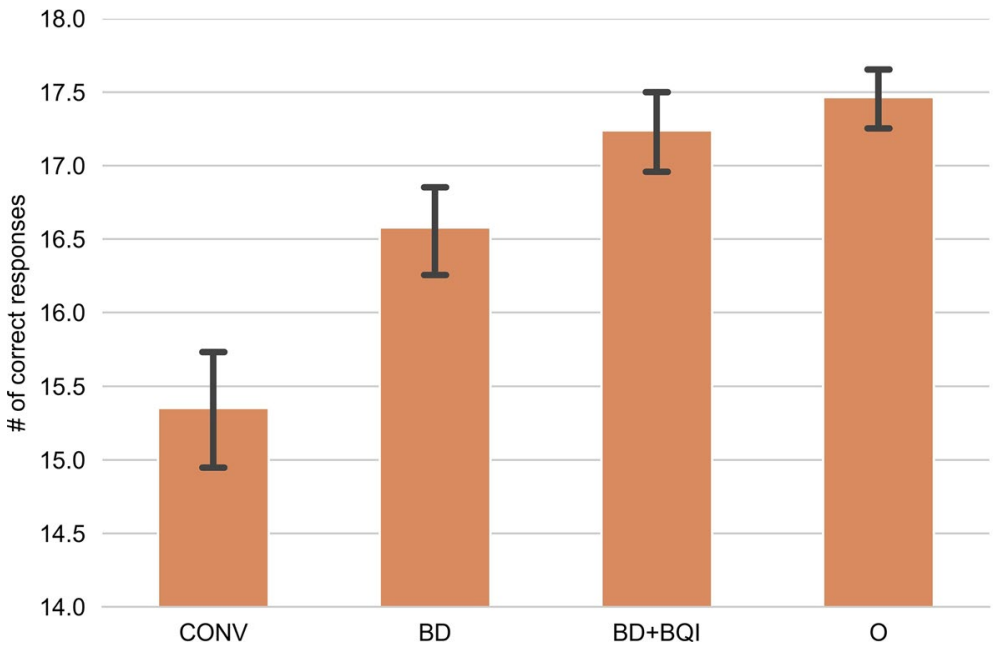

Fig. 9 Average number of correct answers to the Continuous Performance Test in the fourlearning environments. $\mathrm{CONV}=$ conventional classroom; $\mathrm{BD}=$ biophilic designed classroom; $\mathrm{BD}+\mathrm{BQI}=\mathrm{BQI}$ certified biophilic designed classroom; $\mathrm{O}=$ Outdoor

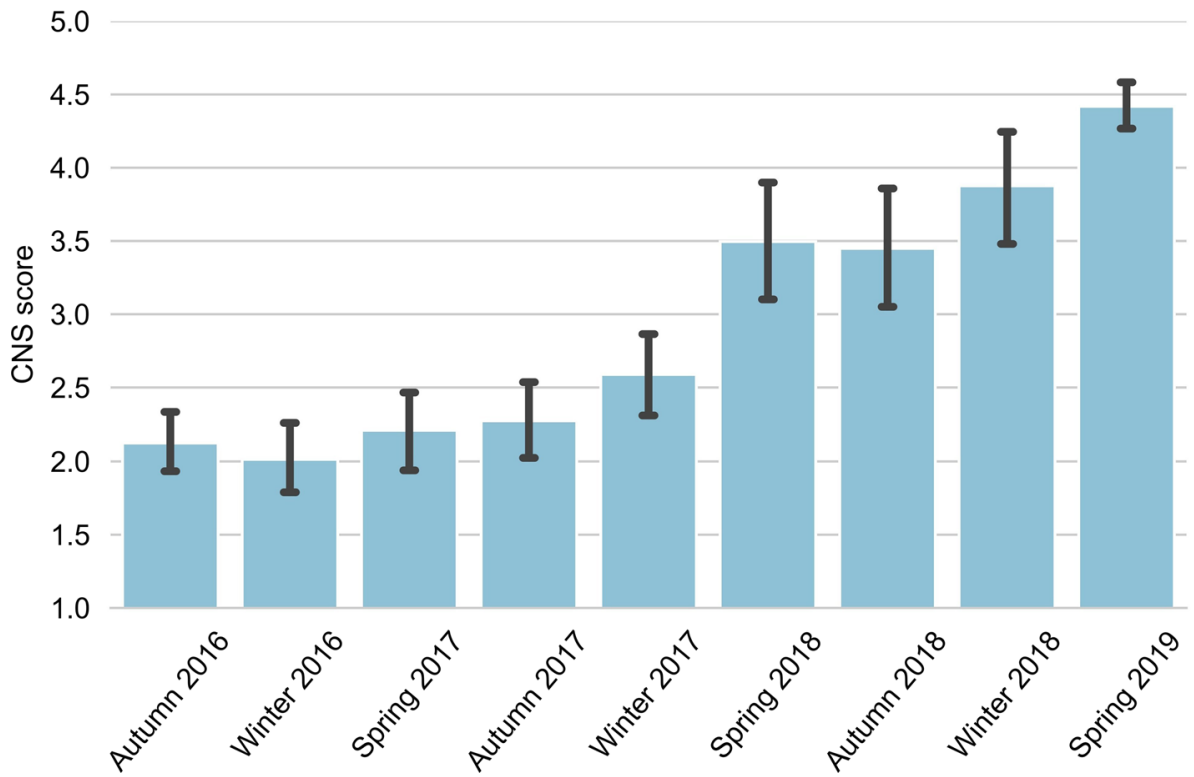

Fig. 10 Average score of the Connectedness to Nature Scale-ch (CNS) from 2016 to 2019; the school's building requalification occurred in the summer of 2017

performance improves when the test is taken in a biophilic designed learning environment, and even more so in the BQI certified environment, where execution time and number of correct responses are close to those of the outdoor learning environment.

From 2016 to 2019, the CNS-ch was administered at three different times for each school year: in autumn, winter and spring, as Fig. 10 shows. Starting in the spring of 
2018 , that is, from the second part of the first school year after the requalification of the indoor environments with biophilic design, the pupils' connection to Nature increased gradually and settled on above-average values for the whole of the next year.

\section{Discussion}

Bracing Biophilia is a broad project that aims to verify the effect of Nature-based $v s$ conventional learning environments on pupils' attentional performance and affiliation with Nature. In particular, in this research study, a conventional learning environment was compared to the biophilic designed, the biophilic designed BQI certified, and the outdoor learning environment.

The results we gathered all go in the same direction: the pupils' perception of restoration follows the same trend as the environmental preference and attention test performance. Pupils prefer outdoor learning environment, and among the indoor environments, pupils prefer the Nature-based learning environments. Basically, results all keep improving as they move on from a conventional learning environment to a learning environment with a biophilic design more and more focussed on Nature. In fact, the learning environment with biophilic design when further improved by adopting the restorative criteria of the BQI shows results closer to the outdoor learning environment, which is the very best for learning.

We observed that continuous and direct exposure to Nature for quite a long time has slowly changed the pupils' feelings of affiliation with Nature. Continuous contact with Nature seems necessary, especially when pupils are confined to indoor learning environments. Biophilic design can reduce the gap between indoor and outdoor natural environments.

The improvements shown by pupils in perception of restoration, in attention test performances and in affiliation with Nature cannot be attributed to cognitive maturation processes, actually the pupils' average age remained constant over the three years.

The most evident limitation of this study is that a very small number of pupils was observed, which does not allow to develop statistical analyses, but only to record trends. This is due to the structural limitations of a rural high mountain school that serves a small community with low population density. In any case, this study allowed us to compare indoor learning environments against a well-preserved natural outdoor learning environment; this comparison would have been impossible in overcrowded urban areas where the natural environment is poorly preserved or even absent. Having a high-quality outdoor learning environment as a reference point allows us to establish a "hierarchy" among indoor environments. Learning environments with biophilic design seem superior to conventional environments for all the parameters we considered. This case study allows us to appreciate the importance of restorative learning environments with biophilic design capable of supporting the learning process and strengthening the feeling of affiliation with Nature and sets the stage for pro-environmental behaviour in adults (Berto \& Barbiero, 2017a). We hope that this pilot study can be considered as an inspiration for larger projects, regardless of the biophilic quality of the outdoor environment. 


\section{Concluding remarks}

What do children need to stimulate their biophilia? First, children need to spend time immersed in Nature. Our experimental observations reveal that teaching activities conducted outdoors in a well-preserved natural area is the most effective way to foster learning processes. This longitudinal case study suggests that the improvements shown by pupils can be attributed to the opportunity they were offered to attend continuously environments that stimulate biophilia. A biophilic designed learning environment provides continuity to their need to get in contact with Nature. Therefore, biophilic designed learning environment is proposed as an Innovative Learning Environment model aimed at supporting the cognitive processes of pupils.

Acknowledgements Bracing Biophilia summarises the results of 'Nuova Architettura Sensibile Alpina' (New Sensitive Alpine Architecture) an applied research programme-Unique Project Code (UPC) B66G15002490006 — of the University of Valle d'Aosta, funded by European Regional Development Fund (ERDF) and European Social Fund (ESF). This article is part of the activities of the project "Green space for active living: older adults' perspectives", funded by the Cariplo Foundation in response to the Call "Social research on aging 2018: people, places and relationships 2018"-UPC G44I18000180005-Ref. Practice 2018-0841.

Open Access This article is licensed under a Creative Commons Attribution 4.0 International License, which permits use, sharing, adaptation, distribution and reproduction in any medium or format, as long as you give appropriate credit to the original author(s) and the source, provide a link to the Creative Commons licence, and indicate if changes were made. The images or other third party material in this article are included in the article's Creative Commons licence, unless indicated otherwise in a credit line to the material. If material is not included in the article's Creative Commons licence and your intended use is not permitted by statutory regulation or exceeds the permitted use, you will need to obtain permission directly from the copyright holder. To view a copy of this licence, visit http://creativecommons.org/licenses/by/4.0/.

\section{References}

Adams, S., \& Savahl, S. (2017). Nature as children's space: A systematic review. The Journal of Environmental Education, 48(5), 291-321. https://doi.org/10.1080/00958964.2017.1366160

Barbiero, G., \& Berto, R. (2016). Introduzione alla biofilia. Carocci, Roma, IT: La relazione con la Natura tra genetica e psicologia.

Barbiero, G., \& Berto, R. (2021). Biophilia as evolutionary adaptation: An onto- and phylogenetic framework for biophilic design. Frontiers in Psychology, 12, 700709. https://doi.org/10.3389/fpsyg.2021.700709

Barbiero, G., Berto, R., Freire, D., Ferrando, M., \& Camino, E. (2014). Unveiling biophilia in children using active silence training: an experimental approach. Visions for Sustainability, 1, 31-38. https://doi.org/10. $13135 / 2384-8677 / 1420$

Barbiero G., Venturella A., Maculan N., Miroglio M., Berto R., and Callegari G. (2017). The Restorative Schoolroom of Gressoney-La-Trinité as an example of biophilic design integrated in energetic efficiency retrofit. Proceedings of the $27^{\text {th }}$ Congress of The Italian Society of Ecology, Napoli, September 12-15, p. 147 .

Barbiero, G (2009). Revealing children's biophilia. In Science, society and sustainability: education and empowerment for an uncertain world. D. Gray, L. Colucci Gray and E. Camino (eds), Routledge, Milton Park, UK, pp. 181-184.

Berto, R. (2005). Exposure to restorative environments helps restore attentional capacity. Journal of Environmental Psychology, 25, 249-259. https://doi.org/10.1016/j.jenvp.2005.07.001

Berto, R. (2014). The role of nature in coping with psycho-physiological stress. A literature review of restorativeness. Behavioral Science, 4, 394-409. https://doi.org/10.3390/bs4040394

Berto, R., Massaccesi, S., \& Pasini, M. (2008). Do eye movements measured across high and low fascination photographs differ? Addressing Kaplan's fascination hypothesis. Journal of Environmental Psychology, 28(2), 185-191. https://doi.org/10.1016/j.jenvp.2007.11.004 
Berto, R., Pasini, M., \& Barbiero, G. (2015). How does psychological restoration work in children? an exploratory study. Journal of Child and Adolescent Behaviour, 3, 200. https://doi.org/10.4172/2375-4494.10002 00

Berto, R., and Barbiero, G. (2017a). How the psychological benefits associated with exposure to Nature can affect pro-environmental behavior. Annals of Cognitive Science, 1(1), 16-20. https://scholars.direct/Artic les/cognitive-science/acs-1-004.php

Berto, R., \& Barbiero, G. (2017b). The biophilic quality index. A tool to improve a building from "green" to restorative. Visions for Sustainability, 8, 38-45. https://doi.org/10.13135/2384-8677/2333

Berto, R., Maculan, N., \& Barbiero, G. (2020). Does sustainability address perceived restoration? An exploratory study on Biosphera 2.0, a net zero energy house. Visions for Sustainability, 13, 17-30. https://doi.org/ $10.13135 / 2384-8677 / 4181$

Bolten, B., \& Barbiero, G. (2020). Biophilic design: How to enhance physical and psychological health and wellbeing in our built environments. Visions for Sustainability, 13, 11-16. https://doi.org/10.1313/2384$8677 / 3829$

Browning, W.D., Ryan, C.O., and Clancy, J.O. (2014). 14 Patterns of Biophilic Design. Terrapin Bright Green, LLC, New York, NY. https://www.terrapinbrightgreen.com/wp-content/uploads/2014/09/14-Patterns-ofBiophilic-Design-Terrapin-2014p.pdf

Camino, E., Barbiero, G., and Marchetti D. (2009). Science Education for Sustainability. Teaching Learning Processes with Science Researchers and Trainee Teachers. In Science, society and sustainability: education and empowerment for an uncertain world. D. Gray, L. Colucci Gray and E. Camino (eds). Routledge, Milton Park, UK, pp. 181-184.

Cornoldi, C., Gardinale, M., Masi, A., \& Pettinò, L. (1996). Impulsività e autocontrollo. Gardolo (TN): Edizioni Erickson.

Dadvand, P., Nieuwenhuijsen, M. J., Esnaola, M., Forns, J., Basagaña, X., Alvarez-Pedrerol, M., Rivas, I., López-Vicente, M., De Castro Pascual, M., Su, J., Jerrett, M., Querol, X., \& Sunyer, J. (2015). Green spaces and cognitive development in primary schoolchildren. Proceedings of the National Academy of Sciences, 112(26), 7937-7942. https://doi.org/10.1073/pnas.1503402112

Hartig, T., Korpela, K., Evans, G. W., \& Gärling, T. (1997). A measure of restorative quality in environments. Scandinavian Housing and Planning Research, 14(4), 175-194. https://doi.org/10.1080/0281573970 8730435

Hartig, T., Bringslimark, T., \& Grindal Patil, G. (2008). Restorative environmental design: What, when, where, and for whom. In S. Kellert, J. Heerwagen, \& P. Mador (Eds.), Biophilic Design (pp. 133-151). John Wiley and Sons.

Hernandez, B., Hidalgo, C., Berto, R., \& Peron, E. (2001). The role of familiarity on the restorative value of a place: Research on a Spanish sample. IAPS Bulletin, SpEcial Issue on Environmental Cognition in Memory of Mimma Peron, 18, 22-24.

Kaplan, S. (1995). The restorative effects of nature: Toward an integrative framework. Journal of Environmental Psychology, 15, 169-182. https://doi.org/10.1016/0272-4944(95)90001-2

Kaplan, S. (2001). Meditation, restoration and the management of mental fatigue. Environment and Behavior, 33(4), 480-506. https://doi.org/10.1177/2F00139160121973106

Kellert, S. R. (2008). Dimensions, Elements and Attributes of Biophilic Design. In S. Kellert, J. Heerwagen, \& P. Mador (Eds.), Biophilic Design (pp. 3-19). John Wiley and Sons.

Kellert, S. R. (2018). Nature by Design. Yale University Press.

Kellert, S. R., \& Wilson, E. O. (1993). The Biophilia Hypothesis. Island Press.

Kuo, M., Browning, M. H., \& Penner, M. L. (2018). Do lessons in nature boost subsequent classroom engagement? Refueling students in flight. Frontiers in Psychology, 8, 2253. https://doi.org/10.3389/fpsyg.2017. 02253

Kuo, M., Barnes, M., \& Jordan, C. (2019). Do experiences with nature promote learning? Converging evidence of a cause-and-effect relationship. Frontiers in Psychology, 10, 305. https://doi.org/10.3389/fpsyg.2019. 00305

Maxwell, L. (2007). Competency in child care settings: The role of the physical environment. Environment and Behavior, 39(2), 229-245. https://doi.org/10.1177/0013916506289976

Mayer, F. S., Frantz, M. P., \& C.M.P. (2004). The connectedness to nature scale: A measure of individuals' feeling in community with nature. Journal of Environmental Psychology, 24(4), 503-515. https://doi.org/10. 1016/j.jenvp.2004.10.001

Moore, G. (1987). The physical environments and cognitive development in child-care centers. In C. Weinstein \& T. David (Eds.), Spaces for children: The built environment and child development (pp. 41-72). Plenum.

Moore, G., \& Sugiyama, T. (2007). The children's physical environment rating scale (CPERS): Reliability and validity for assessing the physical environment of early childhood educational facilities. Children, Youth and Environment, 17(4), 24-53. https://doi.org/10.7721/chilyoutenvi.17.4.0024 
OECD. (2013). Innovative learning environments. Educational Research and Innovation, OECD Publishing, Paris. https://doi.org/10.1787/9789264203488-en

OECD. (2015). Schooling redesigned: Towards innovative learning systems. Educational Research and Innovation, OECD Publishing, Paris. https://doi.org/10.1787/9789264245914-en

OECD. (2017). The OECD handbook for innovative learning environments. Educational Research and Innovation, OECD Publishing, Paris. https://doi.org/10.1787/9789264277274-en

Purcell, T., Peron, E., \& Berto, R. (2001). Why do preferences differ between scene types? Environment and Behavior, 33(1), 93-106. https://doi.org/10.1177/2F00139160121972882

Sturgeon, A. (2017). Creating Biophilic Buildings. Ecotone, Seattle, WA.

Venturella, A., \& Barbiero, G. (2021) Bracing Biophilia: l'esperienza educativa della scuola biofila di Gressoney-La-Trinité. Ecologia della salute, 2, 49-61. http://www.aiems.eu/files/ecologia_della_salute_-_n2. pdf

Wilson, E. O. (1984). Biophilia. Harvard University Press.

Wilson, E. O. (2002). The Future of Life. Knopf, New York, NY: Alfred A.

Publisher's Note Springer Nature remains neutral with regard to jurisdictional claims in published maps and institutional affiliations.

\section{Authors and Affiliations}

\section{Giuseppe Barbiero $^{1} \mathbb{C}^{\circ} \cdot$ Rita Berto $^{1} \cdot$ Alice Venturella $^{1} \cdot$ Nicola Maculan $^{1}$}

1 GREEN LEAF - Groupe de Recherche en Education à l'Environnement et à la Nature, Laboratorio di Ecologia Affettiva, Università della Valle d'Aosta-Université de la Vallée d'Aoste, Strada Cappuccini, 2, 11100 Aosta, Italy 